\title{
ВЛИЯНИЕ ТЕХНОЛОГИЙ ИНТЕРНЕТА ВЕЩЕЙ И БОЛЬШИХ ДАННЫХ НА СОВРЕМЕННУЮ ЭКОНОМИКУ
}

\section{THE IMPACT OF INTERNET OF THINGS AND BIG DATA TECHNOLOGIES ON THE MODERN ECONOMY}

\section{S. Doguchaeva}

Summary. Today, a dynamic ecosystem based on technological IT infrastructure, intuitive devices and interfaces, extensive audience networks and an unlimited amount of content is in demand in companies. The digital economy and the Internet of things technologies make it possible to create new opportunities in working with clients, big data, and innovation management.

New approaches of the Internet of things and Big Data technologies in the modern economy cover the main aspects of the development of network and communication infrastructure. In the digital economy, through close interaction, network and communication infrastructures provide a global platform on which IT companies develop their solution strategies.

Keywords: digital economy, Internet of things, software, network infrastructure, big data, information technology.
B озможность применения Интернета вещей (IoT) и Больших данных (Big data) во многих отраслях экономики, позволяют на сегодняшний день существенно улучшить ИТ-процессы. Внедрение ИТ-инноваций в экономику не простой путь, где специалисты, обладающие навыками внедрения новых методов, способны объединить их компетенции с бизнес-лидерами, способными произвести необходимые организационные изменения.[2]

По мнению ведущих ИТ-аналитиков, одним из основных направлений данной отрасли, является рост Интернета вещей и подключенных устройств, а также ожидаемый всплеск киберрисков, которые могут повлиять на рост цифровой экономики и не только. Поставщики технологий, ведущие экономисты, отраслевые аналитики и правительственные эксперты, указывают на необходимость обеспечения безопасности Интернета вещей в целом. Тем не менее, чтобы действительно способствовать росту Интернета вещей и Больших данных, компаниям следует ввести последовательное обучение сотрудников, включая лучшие практики в области развития новых ИТ-инноваций, что неизменно приведет
Догучаева Светлана Магомедовна

К.ф.-м.н., доцент, Финансовый университет при Правительстве Российской Федерации, г. Москва sv-doguchaeva@yandex.ru

Аннотация. Сегодня динамичная экосистема, основанная на технологической ИТ- инфраструктуре, интуитивных устройствах и интерфейсах, обширных сетях аудитории и неограниченном количестве контента, востребована в компаниях. Цифровая экономика и технологии интернета вещей, позволяют создавать новые возможности в работе с клиентами, большими данными, по управлениям инновациями.

Новые подходы технологий Интернета вещей и Больших данных в современной экономике, охватывают основные аспекты развития сетевой и коммуникационной инфраструктуры. В цифровой экономике, благодаря тесному взаимодействию между собой, сетевые и коммуникационные инфраструктуры обеспечивают глобальную платформу, на которой ИТ-компании разрабатывают стратегии своих решений.

Ключевые слова: цифровая экономика, интернет вещей, программное обеспечение, сетевые инфраструктуры, большие данные, информационные технологии.

к росту развития российской цифровой экономики в целом. [3]

Современный мир благодаря растущей роли цифровой экономики проходит через стадию радикальной трансформации, технологии и инновации перешли в разряд быстрого глобального распространения. Сегодня ІоТ и сенсорные данные, такие как интеллектуальная собственность и конфиденциальные данные клиентов, в основном, направлены на конкурентов. Промышленные организации начинают подготовку, прежде всего, признав реальную возможность инсайдерских угроз, и нахождение новых способов защиты активов как от злонамеренных внешних, так и внутренних угроз. Такие технологии, как искусственный интеллект (AI) в экономике, дополненная реальность (AR) и машинное обучение (ML), сегодня играет все большую роль в промышленных условиях.

Компания по исследованию рынка loT, Analytics в экономике, прогнозирует, что расходы на продукты и услуги Индустрии 4.0 резко возрастут с \$119 млрд. в 2020 году до \$310 млрд. в 2023 году. Компании, которые возглавля- 
ют сбор, получают больше всего от инвестиций в технологии loT, включаят производство, транспорт, логистику и коммунальные услуги - каждый из них, по прогнозам, потратит \$40 млрд. на ІоТ- платформы, системы и услуги к 2022 году.[1]

Для предотвращения интеллектуальных угроз, по мере их возникновения, в промышленных условиях команды по обеспечению безопасности оперативных технологий, все чаще используют механизмы защиты с использованием искусственного интеллекта и Интернета вещей. Экспертные аналитические ИТ-исследования, такие как IDC, показывают, что данные инструменты могут подвергнуться опасности. [4,5] Сегодня по мнению ведущих аналитиков-экономистов, крайне важно, чтобы ИТ-операторы оставались вовлеченными в промышленную среду с интеллектуальными и автоматизированными активами и процессами. Сегодня компании в развитии цифровой экономики, в рамках циклических структур, учитывают человеческий фактор, который сочетает технические подходы, а также аспекты управления с развертыванием и использованием Интернета вещей и Машинного обучения.

По мере того, как все больше устройств Интернета вещей выходят в сеть, идея пограничных вычислений, становится популярной как способ борьбы с большими объемами генерируемых данных, которые в свою очередь, могут существенно повлиять на экономику в целом. В частности, основное внимание уделяется обработке и анализу данных на устройствах, расположенных на краю сети, а не на центральном узле или центре обработки данных. Цель состоит в том, чтобы обеспечить более высокую производительность для снижения эксплуатационных нагрузок и затрат в направлении нового вектора развития российской экономической цифровизации. Сегодня это может усугубляться, при анализе разнообразия случаев ІоТ-устройств, насколько они могут отличаться от более старых, к примеру, унаследованных ИТ-технологиями.[2]

Простое отслеживание и мониторинг устройств может привести к проблемам в ИТ-исследовании, так как сегодня существует проблема дефолта и слабых учетных данных для этих устройств. Но следует заметить, что не все устройства рассматриваются как критические, даже кажущаяся незначительной информация может быть ценной для злоумышленников - к примеру, мониторинг ежедневного использования термостата, который может сигнализировать о нахождении людей в здании. Ведущие экспертные аналитики также сообщают о том, что не следует забывать о физическом риске безопасности вокруг пограничных вычислений, таких как фальсификация и повреждение. Как решения, на базе искусственного интеллекта, так и передовые техноло- гии, обладают огромным потенциалом реализации новых возможностей в современной индустрии цифровой экономики.

Понимание того, что мобильные приложения являются новыми конечными точками в современной экономике, ведет к тому, что ИТ-специалисты переходят к более зрелой стратегии по их развитию и их защите данных. И как следствие, перспективные компании рассматривают данную возможность как доступ к вещам, которые имеют значение, независимо от того, какую мобильную операционную систему или устройство используют его пользователи. [6]

В связи с растущим вниманием к решениям ІоТ-технологий, ИТ-аналитики испытывают необходимость в удовлетворении требований конечных пользователей, в предоставлении безопасных приложений для бизнес-линий и партнеров, а также обеспечении быстрого выхода на рынок, ориентированный на клиентов. Интеллектуальные устройства ІоТ в промышленных условиях изменили точку зрения на среду оперативных технологий. В последнее десятилетие ИТ- специалисты по безопасности сосредоточились на одной общей задаче: выявление и сдерживание нарушений данных, которые сильно влияют на развитие экономики. Экономисты и ИТ- аналитики понимают, что новый рубеж подключенных устройств представляет собой следующее поколение угроз безопасности. В текущем году ИТ-аналитики и ведущие экономисты, увидели четкую тенденцию: безопасность Интернета вещей меняет способы совместной работы информационных и операционных технологий в экономике и не только. Эффективное реагирование на угрозы с учетом специфического контекста, начинается с оценки - понимания текущей стратегии сегментации, оценки слабых мест и построения плана смягчения последствий. [3,9]

Интеллектуальные ІоТ-устройства, такие как энергетика и производство, изменили подход к информационным и операционным технологиям. ІоТ и интеллектуальный мониторинг особенно важны в таком стремлении, и именно поэтому ИТ-практики и экономисты делают серьезные инвестиции в технологии прогнозной аналитики. Решения для прогнозного технического обслуживания могут демонстрировать рентабельность инвестиций, но при реализации таких программ особое внимание должно уделяться безопасности. Неспособность реализовать правильные элементы управления, может фактически повредить доступность и производительность системы, что неизменно скажется на экономике.

Интеллектуальные устройства ІоТ и информационные операционные технологии продолжают интегри- 
роваться и объединяться в цифровых средах организаций, что в свою очередь, существенно может повлиять на экономическую составляющую компаний. ИТ-отделы и группы поддержки осознают важность безопасности в данном процессе, что приводит к смещению акцента ИТ-персонала в сторону сотрудников, которые сосредоточены на производственных вопросах. По мнению ведущих ИТ-специалистов, в компаниях ИТ- отделы, применяя технологии ІоТ, должны выйти за пределы своего фокуса и работать вместе с другими ИТ-коллегами других компаний, понимать роль и приоритет систем и процессов развития цифровой экономики в целом по стране. Это может помочь ИТ-отделам ведущих компаний коррелировать и ускорить оповещения для улучшения решений, основанных на рисках в цифровизации экономики и не только. [3]

По мнению ведущих аналитиков, для того чтобы компании могли обеспечить безопасность и эффективную оптимизацию промышленных операций, им необходимо сделать производственные и охранные данные доступными и удобными для совместного использования в рамках конвергентной архитектуры ИТ-сети, которые часто интегрируются с системами планирования общеорганизационных ресурсов (ERP) и другими системами. Для этого потребуется платформа или набор интегрированных решений, которые могут как принимать данные, так и интегрировать их для расширенной корреляции данных.

Данная концепция, с применением ІоТ-устрвойств и Больших данных, способна в корне изменить экономические и общественные процессы, путем исключения влияния человека на произведения большинства операций. Сегодня по мнению ведущих экономистов - аналитиков, это ключ к быстрому доступу и анализу важных для безопасности производственных данных.[7]

Все данные устройства, с применением Больших данных, генерируют огромные массивы производственных данных, также их можно использовать для мониторинга взломанных учетных данных или несанкционированного доступа. Изучение и анализ производственных или технологических простоев и инцидентов безопасности в конвергентных ИТ-сетях может обеспечить неожиданные корреляции и помочь повысить точность оценки рисков.

Сегодня сотрудникам следует быть готовыми к обнаружению скрытых моментов безопасности, которые они могут пропустить, рассматривая производственные данные и данные безопасности отдельно. Подключенные устройства быстро распространяются, это означает, что ведущие экономисты и ИТ-специалисты находят варианты для потенциального использования технологии Интернета вещей.
ІоТ быстро перешел от простых подключенных к Интернету гаджетов и носимых устройств к более сложным интерактивным функциям, что, в свою очередь, привело к значительному росту цифровой экономики страны. Темпы внедрения технологии различных помощников обогнали смартфоны и планшеты, ведущие ИТ-специалисты предсказывают, что к 2022 году в домах по всему миру появится до 360 миллионов умных динамиков. [8] Устройства с голосовым помощником полагаются на «навыки» или комбинации словесных команд, которые инструктируют помощника выполнять задачу, каждый умный помощник имеет возможность стать еще умнее с помощью Больших данных.

Сегодня все больше специалистов и разработчиков используют наборы инструментов для создания новых навыков, существует неограниченный простор для инноваций, но с небольшими гарантиями или твердым пониманием пользователями рисков, связанных с новой технологией. Аналитические исследования показывают, что технология обработки голоса не всегда правильно интерпретирует команды, такие потенциальные ошибки подвергают пользователей риску активации навыков, которые они не хотели использовать, поэтому открывают новые возможности для использования киберпреступниками.

Сегодня исследование [2,5] предлагает пять основных способов трансформации экономической деятельности с помощью цифровых технологий:

1. Сбор и анализ данных - компании смогут собирать большое количество информации о предпочтениях клиентов, которые могут быть использованы для прогнозирования поведения клиентов и улучшения качества предоставляемых услуг.

2. Персонализация - компании смогут поставлять индивидуальные продукты и услуги. Клиенты ожидают упорядоченного опыта и рассчитывают на то, что продавцы будут обладать соответствующей информацией о своей истории покупок, предпочтениях в выставлении счетов, адресах доставки и других деталях.

3. Экспериментирование и непрерывное развитие - компании смогут использовать большие массивы данных и применять мощные алгоритмы прогнозирования для автоматизации систем и принятия обоснованных решений по производству и распределению ресурсов.

4. Инновации в контрактной деятельности - компании и потребители смогут отслеживать, контролировать и проверять работу других лиц, с которыми они проводят сделки.

5. Устойчивая тенденция информатизации процессов управления дает возможность ИТ-ресурсам взаимодействовать с большей гибкостью, неза- 
висимо от того, где они находятся. Компании смогут легче обслуживать глобальный рынок своих товаров и услуг.

Анализируя работы [6,8] следует сделать вывод, что технологические прорывы в экономике быстро смещают границу между актуальными задачами, выполняемыми людьми, и задачами, выполняемыми машинами и алгоритмами, глобальные рынки труда претерпевают серьезные преобразования. Эти преобразования, при разумном управлении, могут привести к новой эре активной работы, достойных рабочих мест в компаниях и улучшения качества жизни. В противном случае, они могут привести к увеличению раз- рыва в навыках, усилению неравенства и более широкой поляризации.

Сегодня информационно-коммуникационные технологии с навыками цифровой экономики - это формула успеха любой компании. [9] ІоТ- технологии с применением Больших данных, делают упор на инновации, используя новейшие технологии, что помогает стартапам решать более сложные задачи с различными цифровыми перспективами. В цифровую экономическую эпоху, компаниям необходимо стать более инновационными, им практически необходимо оставаться конкурентоспособными в глобальной бизнес-среде, так как именно здесь большую роль играют совместные ИТ-инновации.

\section{ЛИТЕРАТУРА}

1. Тенденции мирового ИТ-рынка// (Электронный ресурс). Режим доступа: http://www.tadviser.ru/index.php// свободный (дата 0бращения 12.04.2020).

2. Интернет вещей и цифровая трансформация экономики // (Электронный ресурс). Режим доступа: http://lib.broadcasting.ru/articles2/tsifrovaya cвободный (дата обращения 15.03.2020).

3. Цифровая трансформация клиентского сервиса // (Электронный ресурс). Режим доступа: https://vc.ru/u/414944-vitaliy-chesnokov/97787-cifrovaya cвободный (дата обращения 01.04.2020).

4. ІоТ-устройства цифровой экономики// (Электронный ресурс). Режим доступа: https://ria.ru/20191230/1562653998.html свободный (дата обращения 27.03.2020).

5. Большие данные в экономике // (Электронный ресурс). Режим доступа: https://data-economy.ru/science свободный (дата 0бращения 07. 04.2020).

6. Цифровые технологии // (Электронный ресурс). Режим доступа: https://data- economy.ru/science // свободный (дата обращения 01. 04.2020).

7. Информационные и ІоТ-технологии// (Электронный ресурс). Режим доступа: https://fb.ru/article/147139/ikt--eto-perspektivyi-razvitiya-ikt cвободный (дата обращения 12.04.2020).

8. Управление базами данных// (Электронный ресурс). Режим доступа: https://finfocus.today/sfery-primeneniya-blokchejna.html свободный (дата обращения 21.03.2020).

9. Ц Цифровизация экономики и Интернета вещей // (Электронный ресурс). Режим доступа: http://bit.samag.ru/uart/more/67 свободный (дата обращения 30.03.2020). 